\title{
SUPORTE A IDOSAS CUIDADORAS DE FAMILIARES DEPENDENTES
}

\section{SUPPORT FOR ELDERLY FEMALE CAREGIVERS OF DEPENDENT FAMILY MEMBERS}

\section{APOYO A CUIDADORAS ANCIANAS DE FAMILIARES DEPENDIENTES}

\author{
Nildete Pereira Gomes ${ }^{1}$ \\ Larissa Chaves Pedreira ${ }^{2}$ \\ Nadirlene Pereira Gomes ${ }^{2}$ \\ Tania Maria de Oliva Menezes ${ }^{2}$ \\ Mateus Vieira Soares ${ }^{3}$ \\ Arianna Oliveira Santana Lopes ${ }^{4}$
}

Como citar este artigo: Gomes NP, Pedreira LC, Gomes NP, Menezes TMO, Soares MV, Lopes AOS. Suporte a idosas cuidadoras de familiares dependentes. Rev baiana enferm. 2019;33:e29899.

Objetivo: conhecer os suportes para as idosas cuidadoras no cuidado de familiares dependentes. Método: pesquisa qualitativa, realizada entre março e junho de 2017 com seis idosas cuidadoras de pessoas dependentes cadastradas no programa público de atenção domiciliar em Salvador, Bahia, Brasil. Os dados das entrevistas foram analisados com base na Análise de Conteúdo de Bardin. Resultados: o estudo apontou que as idosas cuidadoras, no processo de cuidar do ente dependente, contam com o suporte de familiares, cuidadores formais, empregadas domésticas, programa de atendimento domiciliar e o atendimento móvel de urgência 24 horas. Conclusão: as idosas cuidadoras, no processo de cuidar do ente dependente, contavam com diversos suportes, os quais minimizavam a sobrecarga do cuidado e possibilitavam-lhes maior qualidade de vida.

Descritores: Cuidadoras. Equipe de Assistência ao Paciente. Enfermagem Domiciliar. Saúde do Idoso. Enfermagem Geriátrica.

Objective: to know the support for the elderly female caregivers in the care of dependent family members. Method: a qualitative research conducted between March and June 2017 with six elderly female caregivers of dependent people enrolled in the public home care program in Salvador, Babia, Brazil. The interview data were analyzed based on Bardin's Content Analysis. Results: the study showed that, in the process of caring for the dependent, the elderly female caregivers have the support of family members, formal caregivers, domestic workers, home care program and 24-hour mobile emergency care. Conclusion: in the process of caring for the dependent, elderly female caregivers have several supports, which minimize the burden of care and enable them a better quality of life.

Descriptors: Female Caregivers. Patient Care Team. Home Nursing. Elderly Health. Geriatric Nursing.

\footnotetext{
Fisioterapeuta. Mestre em Enfermagem e Saúde. Universidade Federal da Bahia. Salvador, Bahia, Brasil. nildetesaude@yahoo.com.br. https://orcid.org/0000-0002$1690-4122$

2 Enfermeira. Doutora em Enfermagem. Professora da Universidade Federal da Bahia. Salvador, Bahia, Brasil. https://orcid.org/0000-000 I-8939-324X; https://orcid. org/0000-0002-6043-3997; https://orcid.org/0000-000 I-5819-0570

3 Psicólogo. Especialista em Saúde da Pessoa Idosa. Professor na Faculdade de Tecnologia e Ciências. Salvador, Bahia, Brasil. https://orcid.org/0000-000 I-7006-2563

Enfermeira. Mestre em Família na Sociedade Contemporânea. Professora da Faculdade Independente do Nordeste. Universidade Federal da Bahia. Salvador, Bahia, Brasil. https://orcid.org/0000-0003-4990-8506
} 
Objetivo: conocer el apoyo a las cuidadoras ancianas en el cuidado de familiares dependientes. Método: investigación cualitativa realizada entre marzo y junio de 2017 con seis cuidadoras ancianas de personas dependientes registradas en el programa público de atención domiciliaria en Salvador, Bahía, Brasil. Los datos de las entrevistas se analizaron con base en el Análisis de Contenido de Bardin. Resultados: el estudio indicó que, en el proceso de cuidar a la persona dependiente, las cuidadoras ancianas cuentan con el apoyo de familiares, cuidadores formales, empleadas domésticas, del programa de atención domiciliaria y de la atención móvil de urgencia las 24 horas. Conclusión: en el proceso de cuidar a la persona dependiente, las cuidadoras ancianas cuentan con diversos tipos de apoyo, que minimizan la sobrecarga del cuidado y les permiten gozar de una mejor calidad de vida.

Descriptores: Cuidadoras. Equipo de Atención al Paciente. Enfermería Domiciliaria. Salud de los Ancianos. Enfermería Geriátrica.

\section{Introdução}

As alterações do processo da senescência indicam a sobrecarga física e mental decorrente do cuidado ao familiar dependente que se expressa mais intensamente no cuidador idoso. Diante de tal conjuntura, urgem estratégias que favoreçam o suporte a esses cuidadores e consequentemente a promoção da qualidade de vida desses.

Essas alterações do envelhecimento populacional ocorrem também com um crescimento significativo e necessário do número de cuidadores de idosos ${ }^{(1)}$. Com o aumento da expectativa de vida, os cuidadores também vêm se tornando idosos e grande parte desses exerce seu papel de maneira informal, situação apontada na literatura $^{(2)}$. O cuidador é definido como qualquer indivíduo, da família ou da comunidade, que exerça o cuidado para com a pessoa dependente sem qualquer orientação ou preparo ${ }^{(3)}$. Os cuidadores informais diferenciam-se dos formais, pois os últimos são capacitados por meio de cursos, que os prepararam para prestar o cuidado. Por isso, são remunerados por seu trabalho ${ }^{(3)}$.

No âmbito do cuidado informal, torna-se necessário pontuar a realidade nacional, no que tange ao despreparo dos cuidadores para a realização das tarefas demandadas. Estudo nacional realizado com 20 cuidadoras de idosos, em que a maioria apresentava idade acima de 50 anos, evidenciou que elas não receberam capacitações e encontravam-se despreparadas para exercer o cuidado do ente familiar ${ }^{(4)}$. Outro estudo alerta que os cuidadores precisam ser orientados e treinados para realizar o cuidado do familiar dependente ${ }^{(5)}$.
Somado ao exercício do cuidado ao ente sem qualquer preparo ou treinamento, os cuidadores vivenciam um cotidiano de sobrecarga de trabalho, muitas vezes com pouco ou nenhuma forma de suporte. Para além das tarefas domésticas, dentre as atividades geralmente realizadas pelos cuidadores em relação ao idoso, encontram-se: preparar o alimento, dar banho, ministrar medicamentos, trocar fraldas entre outras, além da gestão desse cuidado( ${ }^{(5)}$.

Todas essas tarefas são realizadas, quase sempre, sem qualquer auxílio, deixando esses cuidadores vulneráveis ao comprometimento da sua saúde ${ }^{(4)}$. Tal situação também foi revelada em um estudo longitudinal, com mulheres que tinham, em média, 53,2 anos e cuidavam dos sogros e pais. Nesse estudo, os autores alertaram que a prestação dos cuidados informais provocou impactos na saúde dessas pessoas, como surgimento de sintomas psíquicos, agravamento de doenças preexistentes além do risco de adoecimento e acometimento por doenças osteomusculares $^{(6)}$.

Desempenhar o papel de cuidador informal é uma tarefa árdua, independentemente da idade, e exige habilidades ${ }^{(1)}$. Contudo, cuidadores com idade mais avançada apresentam peculiaridades que podem iniciar, ou até mesmo agravar, problemas de saúde já existentes, ocasionando limitações e dificultando a realização de certas tarefas $^{(7)}$. Isso relaciona-se à sobrecarga do trabalho, de forma que os cuidadores idosos lidam com as alterações próprias do seu processo de 
senescência, visto que, na terceira idade, é maior a ocorrência de doenças crônicas.

Estudo realizado na Ásia, com 285 cuidadores informais, no qual mais da metade apresentava idade entre 40 e 65 anos, concluiu que esses possuíam algum comprometimento para a saúde de ordem física, a exemplo da mobilidade, bem como psíquicas, como a angústia, que comprometeram a sua qualidade de vida ${ }^{(8)}$. No Brasil, pesquisa realizada com 99 cuidadores idosos apontou que apresentavam problemas de saúde, a exemplo da dor, problemas de coluna, hipertensão arterial sistêmica e insônia ${ }^{(7)}$. Diante de tais agravos, torna-se necessário um olhar direcionado ao cuidador idoso, visto que estão mais vulneráveis ao desenvolvimento e/ou agravamento de problemas físicos e emocionais pelo ato de cuidar.

É salutar pensar na complexidade existente quando o cuidado é desempenhado por alguém que está vivenciando o envelhecimento, sobretudo quando o cuidado é exercido exclusiva ou quase que exclusivamente por essa pessoa. Entendendo que o processo de cuidar sozinho do familiar dependente pode ocasionar repercussões para a vida da pessoa idosa cuidadora, a pesquisa tem como objetivo conhecer os suportes para as idosas cuidadoras no cuidado de familiares dependentes.

\section{Método}

Trata-se de uma pesquisa qualitativa, realizada com idosas cuidadoras de pessoas dependentes cadastradas em uma das bases do programa de atenção domiciliar denominado "Melhor em Casa”, programa público do Governo Federal, cujas bases situam-se em hospitais públicos de grande porte em Salvador, Bahia, Brasil. Cada base conta com o suporte de uma equipe multiprofissional, constituída por médicos, enfermeira, fisioterapeuta dentre outros profissionais ${ }^{(9)}$.

Como os cuidadores foram majoritariamente mulheres, seguindo o perfil de cuidadores relatado na literatura ${ }^{(1,7,10)}$ serão abordadas, a partir de agora, no sexo feminino. Todas as cuidadoras assistiam familiares cadastrados em uma das bases do referido programa. Foram incluídas aquelas com idade a partir de 60 anos, e que prestassem cuidados ao seu familiar dependente.

A coleta de dados iniciou-se por meio de consulta em todos os 53 prontuários das pessoas cadastradas na base lócus da pesquisa, os quais continham um instrumento chamado Avaliação Social de Elegibilidade, preenchido pelo assistente social. Essa ficha continha informações de todos os moradores do recinto, idade, cuidador responsável, que poderia ou não ser um familiar ${ }^{(3)}$. Durante essa busca, encontrou-se apenas o registro de uma idosa cuidadora, sendo necessária uma nova consulta aos prontuários, com foco na identificação de idosos no seio familiar, possíveis cuidadores, sendo localizadas dez situações. Para identificar se essas pessoas idosas exerciam ou não o cuidado direto ao familiar dependente, realizou-se contato telefônico e constatou-se que sete assumiam o cuidado aos seus entes, totalizando oito idosas cuidadoras. Destas, duas não aceitaram participar e as outras seis concordaram e assinaram o Termo de Consentimento Livre e Esclarecido.

Para a coleta dos dados, foi realizada uma entrevista semiestruturada, composta pela caracterização dos participantes com relação à sua saúde e pelas seguintes questões norteadoras: conte pra mim cada cuidado que você presta ao seu familiar durante todo o dia; me fale sobre as repercussões para sua saúde do cuidado prestado; conte pra mim como você percebe a sua saúde antes e depois do cuidado ao seu familiar.

As entrevistas foram realizadas no domicílio onde familiares dependentes residiam, entre março e junho de 2017. Estas foram gravadas e posteriormente transcritas. Para garantir o anonimato, utilizaram-se nomes fictícios de flores, por entender-se que ambas são delicadas e transmitem vitalidade, elemento essencial para o cuidado de pessoas dependentes.

Os dados foram organizados de acordo com as orientações da Análise de Conteúdo proposta por Bardin, composta por três etapas: pré-análise, exploração do material e tratamento dos resultados. Desta forma, encontraram-se cinco categorias para análise e discussão: suporte de 
familiares; suporte de cuidadores formais; suporte de empregadas domésticas; suporte do programa de atendimento domiciliar; e suporte de atendimento móvel de urgência 24 horas.

Esta pesquisa foi aprovada pelo Comitê de Ética em Pesquisa, sob Parecer no ${ }^{\circ}$ 1.762.501, em 5/10/2016. Trata-se de recorte de uma dissertação de mestrado que objetivou conhecer as implicações relacionadas ao sistema osteomuscular vivenciadas por idosos cuidadores de pessoas com comprometimento da capacidade funcional.

\section{Resultados}

As seis colaboradoras do estudo tinham idade entre 60 e 79 anos, exerciam o cuidado ao ente familiar nos 7 dias da semana e o tempo médio de dedicação variou entre 1 ano e 5 meses (17 meses) a 6 anos (72 meses). Todas as cuidadoras contavam com o suporte do programa de atenção domiciliar e do atendimento móvel de urgência 24 horas. Dentre elas, 2 custeavam o serviço privado, 4 recebiam o auxílio de familiares, 3 de cuidadoras formais e 3 de empregadas domésticas (Quadro 1).

Quadro 1 - Caracterização de idosas cuidadoras de familiares dependentes relacionada aos aspectos sociodemográficos, de saúde e do processo de cuidado

\begin{tabular}{|c|c|c|c|c|c|c|}
\hline Variáveis Codinome & Girassol & Jasmim & Margarida & Orquídea & Rosa & Tulipa \\
\hline Idade (anos) & 73 & 72 & 79 & 63 & 63 & 60 \\
\hline Sexo & Feminino & Feminino & Feminino & Feminino & Feminino & Feminino \\
\hline $\begin{array}{l}\text { Tempo de cuidado (hora)/ } \\
\text { dia }\end{array}$ & 14 & 14 & 16 & 18 & 18 & 16 \\
\hline Tempo de cuidado (meses) & 54 & 36 & 36 & 48 & 72 & 17 \\
\hline Suporte do programa & Sim & Sim & Sim & Sim & Sim & Sim \\
\hline $\begin{array}{l}\text { Suporte do atendimento } \\
\text { móvel }\end{array}$ & $\operatorname{Sim}$ & $\operatorname{Sim}$ & $\operatorname{Sim}$ & $\operatorname{Sim}$ & $\operatorname{Sim}$ & Sim \\
\hline Suporte familiar & Não & Não & Filha & $\begin{array}{l}\text { Irmã } \\
\text { sobrinho }\end{array}$ & Irmã & Esposo \\
\hline Suporte de cuidadora (n) & Não & $\operatorname{Sim}-2$ & Não & $\operatorname{Sim}-1$ & Não & $\operatorname{Sim}-1$ \\
\hline Suporte de empregada (n) & Não & $\operatorname{Sim}-2$ & Não & $\operatorname{Sim}-1$ & $\operatorname{Sim}-1$ & Não \\
\hline Orientação profissional & Sim & Sim & Não & Não & Sim & Sim \\
\hline
\end{tabular}

Fonte: Elaboração própria.

\section{Suporte de familiares}

O estudo revela que, no processo de cuidado dos entes com dependência, as idosas cuidadoras contavam com o apoio de familiares nas tarefas específicas, como higiene e medicação. Importante ressaltar que tais auxílios, que aliviavam a carga física e emocional, não se limitavam aos familiares de primeiro grau, contemplando ainda o cuidado realizado pelos homens, inclusive sem vínculo consanguíneo, como genros.

Minha irmã e meu sobrinho me ajudam muito. Fizemos uma tabela e quem estivesse com ela, ajudava em tudo que precisava: trocar a fralda, mudar de decúbito, banho. (Orquídea, 63 anos, cuidadora de mãe de 91 anos).
[...] meu marido e minha irmã me ajudam. Ela vem duas vezes por semana [...] dá os remédios, observa se precisa trocar fralda ou posição e ainda anota tudo no caderno para eu saber. Fico despreocupada quando ela está aqui, pois, além de me ajudar, eu confio nela! [...] como eu durmo muito tarde, meu marido é quem cuida dele até as 8 boras e só me acorda antes se precisar aspirá-lo, porque isso só eu sei fazer. (Rosa, 63 anos, cuidadora de filho de 31 anos).

\section{Suporte de cuidadores formais}

Ao alertar para os custos que permeiam a contratação de um profissional cuidador formal, o estudo alude à sua relevância na realização das tarefas demandadas pelo ente dependente, desde a companhia até a realização de cuidados 
técnicos, por vezes até incomuns no cotidiano da idosa, como a nutrição enteral. Esse suporte, que por vezes transcende o fazer técnico, visto que se revela também afetuoso, tranquiliza as idosas cuidadoras de modo que, por vezes, conseguem voltar-se para o cuidado de si mesmas.

Ter um cuidador é necessário, porque não sabemos fazer algumas técnicas. Elas limpam, dão o banbo, fazem os curativos, alimentam pela sonda e fazem companbia para ela [...] eu fico mais na parte de supervisão e, assim, às vezes, tenho tempo para mim. (Jasmim, 72 anos, cuidadora de mãe de 98 anos).

Como eu trabalho, contratei uma cuidadora para o dia. Como o dinheiro dela [mãe] é pouco, conseguimos pagar, porque usamos o nosso e também temos a ajuda de um dos irmãos, embora nenhum vem participar do cuidado. Ela cuida com tanto carinho que parece uma filha. Com a ajuda dela, eu consigo me controlar mais emocionalmente, porque é muito difícil cuidar de minha mãe nesse estado [choro]. (Tulipa, 60 anos, cuidadora de mãe de 86 anos).

\section{Suporte de empregadas domésticas}

Os depoimentos também evidenciaram a importância do apoio de trabalhadoras domésticas, cujas ações não se limitam às tarefas de casa, visto que auxiliam as idosas cuidadoras também no cuidado direto ao ente dependente. Esse suporte favorece ainda a disponibilidade de tempo, para que a cuidadora realize suas demandas pessoais.

Eu consigo cuidar dele, porque tenbo o apoio de duas pessoas nas tarefas domésticas. E quando preciso, elas também me ajudam com ele: tirá-lo da cama para a cadeira, trocar a fralda. (Rosa, 63 anos, cuidadora de filho de 31 anos).

São duas empregadas que se revezam [...] elas cuidam da casa, da roupa e da comida [...] assim eu fico mais folgada para fazer minhas coisas. (Jasmim, 72 anos, cuidadora de mãe de 98 anos).

\section{Suporte do programa de atendimento domiciliar}

O programa de atenção domiciliar é visto pelas idosas cuidadoras como um importante recurso para a continuidade dos cuidados profissionais prestados ao dependente, pois, além de prestar orientações, também disponibiliza atendimento domiciliar multiprofissional. É notória a relevância desse programa governamental que, ao disponibilizar recursos humanos, materiais e medicamentos, representa um suporte também financeiro, sobretudo para as famílias cuja renda impossibilita custear tal assistência.

Quando ele saiu do hospital, o programa prestou toda assistência [...] tinha o médico, a enfermeira, a fisioterapeuta [...] também orientavam a mim e a ele como fazer cada coisa. Não paguei nada, porque era tudo da responsabilidade do programa. E isso é ótimo, porque o dinheiro é pouco. (Margarida, 79 anos, cuidadora de neto de 19 anos).

[...] quando precisava de algo, ligava para o programa e a enfermeira mandava trazer todo o material necessário [...] agora que desvincularam ele, tudo está muito difícil. Não tenho como levá-lo ao serviço de saúde, porque ele é tetraplégico e o dinheiro é pouco para comprar tanta coisa. Eu sinto muita falta do programa! (Girassol, 73 anos, cuidadora de filho de 49 anos).

\section{Suporte de atendimento móvel de urgência}

\section{4 horas}

As idosas cuidadoras atribuem importância ao serviço móvel de urgência e consideram-no acessível e resolutivo. Para as entrevistadas, poder contar com esse suporte, seja gratuito ou privado, ajuda a diminuir a ansiedade e a angústia diante das demandas de urgência e emergência.

\footnotetext{
Chamei a ambulância, porque ele estava muito agitado, nervoso. Eles vieram, medicaram, e ele melhorou. Eu gostei muito! (Girassol, 73 anos, cuidadora de filho de 49 anos)

Se ela precisar, eu chamo a ambulância 24 horas [...] eles chegam rápido e atendem bem [...] em alguns casos, até falam o que eu devo fazer pelo telefone. Essas orientações podem salvar a vida! Uma vez, eles me orientaram o que fazer e ela melhorou. Se eu não tivesse esse apoio, eu não saberia como lidar com essa situação. (Tulipa, 60 anos, cuidadora de mãe de 86 anos).
}

\section{Discussão}

O estudo revelou que, no processo de cuidado prestado ao ente com dependência, as idosas cuidadoras contam com diversas formas de suporte, dentre as quais o apoio familiar, perpassando por diferentes graus de parentesco. Estudo realizado com 86 cuidadores de idosos com idade média de 56,5 anos mostrou que 55,8\% recebiam ajuda de algum familiar ${ }^{(5)}$. Importante observar que, nesta pesquisa, a sensibilidade do familiar para contribuir com as tarefas cotidianas demandadas pela pessoa com dependência impactou na melhoria da qualidade do 
cuidador responsável, favorecendo a redução da sua sobrecarga física e mental, conforme expressado nas falas.

Um resultado positivo da colaboração de familiares na melhoria da qualidade de vida dos cuidadores foi relatada em pesquisa desenvolvida no Vietnã, onde, ao final de intervenções por meio de grupo focal, com participação de 21 interessados, dentre eles cuidadores familiares, profissionais e líderes comunitários, pontuou-se a necessidade de outros membros da família dividirem as responsabilidades de cuidado aos seus entes ${ }^{(11)}$.

A despeito desse apoio, outra pesquisa aponta a dificuldade do suporte em algumas famílias que relataram conflitos domésticos e afastamento dos membros durante o cuidado ao ente, recaindo a responsabilidade de cuidar apenas sobre um familiar ${ }^{(12)}$. Tal cenário sinaliza a necessidade de ações profissionais, seja na comunidade, em visitas domiciliares, seja na instituição, que trabalhem com a família ou na formação de redes de apoio ao cuidador, mostrando a necessidade da responsabilidade compartilhada de uma família, bem como a criação de estratégias de resolução de conflitos que harmonizem a relação familiar em prol do cuidado à pessoa dependente.

Chama atenção que, das seis cuidadoras entrevistadas, metade pôde contar com a ajuda de homens, inclusive esposos. Estudo realizado no México com cuidadores familiares homens, com idade entre 29 e 86 anos, mostrou o entendimento desses de que não é obrigação apenas da mulher realizar o cuidado ao familiar, muito menos sozinhas. Essa pesquisa coloca em pauta o comprometimento masculino para com as suas esposas, visto que demonstram parceria em momentos delicados ${ }^{(13)}$, situação também experienciada por duas cuidadoras entrevistadas.

O cuidado prestado às pessoas dependentes, ou não, conduz à reflexão sobre as construções sociais ancoradas nas desigualdades de gênero, em que tal papel é entendido como inerente à figura feminina, não sendo uma conduta habitual no universo masculino, conforme ratifica pesquisa desenvolvida com dez cônjuges de cuidadores familiares que admitem não participar da divisão de responsabilidades e/ou tarefas de cuidados ao ente ${ }^{(14)}$. Em consonância com esse resultado, pesquisa realizada com 14 homens desvela que, embora declarem ajudar nas tarefas de cuidado com o filho, eles entendem ser este um papel da figura feminina, ao contrário da provisão do sustento da família, que é de sua responsabilidade ${ }^{(15)}$.

Essa educação social de gênero, responsável pela assimetria entre homens e mulheres, sustenta e contribui para a hegemonia de mulheres assumindo o papel de cuidadoras responsáveis, enquanto os homens, quando presentes, responsabilizam-se pelo suporte financeiro. Tal realidade, nesta pesquisa, é experienciada, por exemplo, por Tulipa, cujo apoio do irmão limitou-se à disponibilização de recurso financeiro, sem o qual não conseguiria arcar com os serviços de uma cuidadora formal. Das seis cuidadoras entrevistadas, metade não dispõe de recursos para contratar um cuidador formal, fato que é também confirmado em outro estudo ${ }^{(10)}$. Dessa forma, o recurso financeiro pode contribuir para aliviar a sobrecarga física, contudo nem sempre reduz a sobrecarga emocional.

Pesquisa nacional com 33 cuidadores de pacientes com dores crônicas revelou que apenas $3 \%$ eram remunerados, o que confirma a dificuldade financeira por parte do familiar responsável, para contar com o suporte de um cuidador formal $^{(16)}$. Cabe ressaltar a importância desse profissional para a ajuda nas demandas específicas do cuidado, o que também foi apontado em estudo realizado com 33 cuidadores em São Paulo, dos quais 16 formais, que assumiam, dentre outras atividades, o preparo de medicamentos, punções, coleta de exames e verificação de sinais vitais ${ }^{(17)}$.

Vale salientar que as atividades dos profissionais cuidadores formais não se limitam às habilidades técnicas, pois o estudo revelou um vínculo afetivo com a pessoa dependente. Essa perspectiva ampliada considera que o trabalho do cuidador engloba as interfaces do afeto, inteligência e subjetividade ${ }^{(18)}$. Isso favorece que a idosa responsável tenha mais confiança no 
trabalhador e, consequentemente, possa estar menos presente no processo de cuidar do ente.

A tranquilidade experienciada pela cuidadora responsável, por confiar na cuidadora formal, tende a ser percebida também diante da presença de empregadas domésticas, realidade de três entrevistadas. Nesse caso, a redução da carga de trabalho ocorre graças ao apoio das empregadas que assumem as tarefas do lar, a exemplo de lavar, passar, cozinhar, limpar e, por vezes, ajudam no cuidado com a pessoa dependente. Corrobora esse resultado, estudo sobre as interações entre empregadas e patroas, que apontou a atuação dessas funcionárias como contributiva para que os membros da família pudessem desempenhar funções externas às atividades do $\operatorname{lar}{ }^{(19)}$.

No entanto, esse cuidado compartilhado com um profissional remunerado é uma realidade distante nas relações de cuidado com idosos de baixa renda, conforme estudo realizado na Bahia. Evidenciou-se que essa tarefa de cuidador configura-se de forma isolada, e que as dificuldades socioeconômicas dificultam a contratação de um profissional especializado que auxilie no cuidado. Entretanto, programa de atendimento domiciliar é suporte disponível para todas as cuidadoras. Um dos pontos relevantes desse serviço deve-se à oferta de materiais sem custos adicionais, não gerando ônus para a família, que muitas vezes lida com dificuldades para adquirir esses insumos ${ }^{(10)}$.

Estudo realizado com cuidadores de familiares dependentes em Portugal e no Brasil confirma a relevância desses programas para a redução dos custos financeiros, visto que disponibilizam, para além de equipamentos, assistência e orientações ${ }^{(12)}$. Pesquisa que defende a necessidade da presença da enfermeira no atendimento domiciliar confirma que esse serviço desenvolve ações assistenciais, administrativas e educacionais ${ }^{(20)}$. Nesse sentido, os achados revelam que o programa disponibiliza a prestação do serviço especializado da equipe multiprofissional no próprio domicílio, além de orientações, o que facilita o cuidado, pois muitas das pessoas dependentes apresentam limitações importantes, dificultando o seu deslocamento até o serviço de saúde.

Fica notória a importância de um programa de atendimento domiciliar, não apenas para a pessoa dependente, que receberá o cuidado direto, mas também para o familiar responsável, visto que tal suporte o isenta de perda de tempo para provisão de medicamentos e atendimento profissional nas diversas áreas, o que requereria ainda gastos financeiros com aquisição de insumos e/ou deslocamentos. Atrelado a esses aspectos, o serviço de atendimento domiciliar ainda contribui para a realização de procedimentos e técnicas seguras, principalmente no que tange às técnicas de mobilidade, no manuseio de dispositivos e na administração de medicações que os cuidadores apontam como as maiores dificuldades do cuidado. Nesses aspectos, avaliam a assistência domiciliar como satisfatória $^{(21)}$.

Pesquisa bibliográfica realizada na base de dados National Library of Medicine National Institutes of Health (PUBMED) revelou que a atenção domiciliar no cenário mundial está mais voltada para pacientes em cuidados paliativos $^{(22)}$. No Brasil, contempla atividades voltadas para pessoas que apresentam dificuldades temporárias ou definitivas nos diferentes níveis, de forma a proporcionar o cuidado no seio familiar, evitando hospitalização e riscos de infecções ${ }^{(9)}$.

Assim como a assistência do programa de atendimento domiciliar, o atendimento móvel de urgência 24 horas configura-se enquanto um serviço importante e resolutivo, conforme expressam as falas das cuidadoras. Estudo nacional realizado com oito familiares de pacientes críticos que foram atendidos pela equipe do Serviço de Atendimento Móvel de Urgência do Paraná, mostrou que esses avaliaram as atividades da equipe de forma positiva, ressaltando a agilidade e qualidade no atendimento ${ }^{(23)}$. Contar com o suporte de um serviço que tem como principal ação prestar uma assistência especializada no local da ocorrência é essencial para a promoção de conforto e segurança à família, sobretudo diante do preparo profissional para lidar com questões de maior gravidade. 
Considerando a sobrecarga de tarefas e a responsabilidade de um cuidador familiar responsável, sobretudo diante das demandas da pessoa acamada, os suportes aqui apresentados são essenciais não apenas para a pessoa dependente, como também para o familiar responsável. Isto porque as tarefas do cuidado englobam uma gama de fatores, como o econômico, o temporal, a reorganização familiar e pessoal, que impactam diretamente na qualidade de vida do cuidador $^{(1)}$. No Brasil, é urgente o apoio às famílias que cuidam de pessoas dependentes, visto que o país apresenta frágil organização da rede de atenção à saúde, com número insuficiente de profissionais comprometidos em ajudar o cuidador familiar, e baixa cobertura, quando comparada às necessidades demandadas pelos entes dependentes $^{(24)}$.

Todavia, estudo destaca a necessidade de uma rede de apoio para os cuidadores familiares, que os auxilie no cuidado ao ente e contemple o suporte informal e formal, além de prestar atendimento em saúde e possuam estratégias que assegurem informação e comunicação por parte da equipe ${ }^{(12)}$. Tal suporte tem seu valor para melhorar a qualidade de vida do cuidador, deixando-o mais livre para atender suas demandas pessoais, bem como reduzir e/ou anular o adoecimento físico e emocional, principalmente quando se trata de pessoa idosa já susceptível às alterações próprias do processo de senescência e, portanto, mais predisposta a apresentar problemas de saúde, como as doenças crônicas osteomusculares $^{(25)}$.

Embora o estudo tenha limites, por não permitir identificar a qualidade das relações entre os membros da família, que justifique o grau de apoio à cuidadora responsável, e considerando as não raras situações de conflitos familiares relacionadas à negligência do cuidado, torna-se fundamental o incentivo à criação de espaços de discussão acerca de estratégias que viabilizem o apoio para a idosa cuidadora. Acredita-se que o desenvolvimento de ações de interação entre profissional e familiares possa favorecer o processo de redução de sua carga de trabalho relacionada ao cuidado direto com o ente dependente.

\section{Conclusão}

O estudo apontou que as idosas cuidadoras contavam com o suporte de familiares, empregada doméstica e cuidador formal para exercer o cuidado. Outras bases identificadas foram os dispositivos de atenção domiciliar e serviço móvel de urgência e emergência que, por meio de protocolos e estratégias previamente construídas por políticas públicas, possibilitam o acolhimento e o apoio às idosas cuidadoras nas demandas relacionadas ao exercício do cuidado.

Diante o exposto, urgem ações que assegurem à pessoa dependente, em especial àquelas cujas cuidadoras são pessoas idosas, o direito de acesso a serviços no âmbito domiciliar, não apenas para o atendimento às suas necessidades de saúde, crônicas ou agudas, como também às demandas biopsicossociais que, quando atendidas, favorecem o envelhecimento saudável. Vale ressaltar a importância da atuação multiprofissional para o suporte ao cuidador no domicílio, em especial a enfermagem, pelo contato mais frequente e próximo, sendo essencial para o processo de orientação do cuidado.

\section{Colaborações:}

1 - concepção, projeto, análise e interpretação dos dados: Nildete Pereira Gomes, Mateus Vieira Soares e Arianna Oliveira Santana Lopes;

2 - redação do artigo e revisão crítica relevante do conteúdo intelectual: Nildete Pereira Gomes, Larissa Chaves Pedreira, Nadirlene Pereira Gomes e Tania Maria de Oliva Menezes;

3 - aprovação final da versão a ser publicada: Larissa Chaves Pedreira, Nadirlene Pereira Gomes e Tania Maria de Oliva Menezes.

\section{Referências}

1. Anjos KF, Boery RNSO, Pereira R. Qualidade de vida de cuidadores familiares de idosos dependentes no domicílio. Texto Contexto Enferm [Internet]. 2014 [cited 2018 Sep 10];23(3):600-8. 
Available from: http://www.scielo.br/pdf/tce/ v23n3/pt_0104-0707-tce-23-03-00600.pdf

2. Butler SS. Older women doing home care: Exploitation or ideal job? J Gerontol Social Work. [Internet]. 2013 [cited 2018 Sep 7];56(4):299-317. Available from: https://www.ncbi.nlm.nih.gov/ pmc/articles/PMC3711477/

3. Brasil. Ministério da Saúde. Departamento de Atenção Básica. A segurança do hospital no conforto do seu lar. Caderno de atenção domiciliar. Vol. 1. Brasília; 2012.

4. Gutierrez LLP, Fernandes NRM, Mascarenhas M. Caracterização de cuidadores de idosos da região metropolitana de Porto Alegre (RS): perfil do cuidado. Saúde debate [Internet]. 2017 [cited 2018 Oct 2];(114):885-98. Available from: https://www. scielosp.org/article/ssm/content/raw/?resource_ ssm_path=/media/assets/sdeb/v41n114/01031104-sdeb-41-114-0885.pdf

5. Jesus ITM, Orlandi AAS, Zazzetta MS. Sobrecarga, perfil e cuidado: cuidadores de idosos em vulnerabilidade social. Rev Bras Geriatr Gerontol [Internet]. 2018 [cited 2018 Sep 12];(2):194204. Available from: http://www.scielo.br/ scielo.php?script $=$ sci_arttext\&pid=S1809$98232018000200194 \& \operatorname{lng}=p t \& n r m=$ iso $\& \operatorname{tn} n$ $\mathrm{g}=\mathrm{pt}$

6. Kyung Y, Norton EC, Stearns SC, Van Houtven $\mathrm{CH}$. Informal care and caregiver's health. Health Econ [Internet]. 2015 [cited 2018 Sep 12];(2):22437. Available from: https://www.ncbi.nlm.nih.gov/ pmc/articles/PMC4201633/

7. Brigola AG, Luchesi BM, Rossetti ES, Mioshi E, Inouye K, Pavarini SCI. Perfil de saúde de cuidadores familiares de idosos e sua relação com variáveis do cuidado: um estudo no contexto rural. Rev Bras Geriatr Gerontol [Internet]. 2017 [cited 2018 Sep 10];(3):409-20. Available from: http://www.scielo.br/scielo.php?pid=S180998232017000300409\&script=sci_arttext\&tlng=pt

8. Sambasivam R, Liu J, Vaingankar JA, Ong HL, Tan ME, Fauziana R, et al. The hidden patient: chronic physical morbidity, psychological distress, and quality of life in caregivers of older adults. Psychogeriatrics [Internet]. 2019 Jan [cited 2018 Oct 23];19(1):65-72. Available from: https://www. ncbi.nlm.nih.gov/pubmed/30182505

9. Brasil. Ministério da Saúde. Portaria no 825 , de 25 de abril de 2016. Redefine a Atenção Domiciliar no âmbito do Sistema Único de Saúde (SUS) e atualiza as equipes habilitadas. Brasília, DF;
2016 [cited 2018 Oct 20]. Available from: http:// bvsms.saude.gov.br/bvs/saudelegis/gm/2016/ prt0825_25_04_2016.html

10. Almeida LD, Menezes TM, Freitas AV, Pedreira LC. Características sociais e demográficas de idosos cuidadores e motivos para cuidar da pessoa idosa em domicílio. REME rev min enferm [Internet]. 2018 [cited 2018 Sep 10];22:e-1074. Available from: http://www.reme.org.br/artigo/detalhes/1212

11. Meyer OL, Fukurai M, Ho J, Limtiaco P, Nguyen HH, Dang J, et al. Dementia caregiver intervention development and adaptation in the Vietnamese American community: A qualitative study. Dementia [Internet]. 2018 [cited 2018 Sep 15]. Available from: https://www.ncbi.nlm.nih.gov/pubmed/30081663

12. Fernandes CS, Margareth Â, Martins MM. Cuidadores familiares de idosos dependentes: mesmas necessidades, diferentes contextos: uma análise de grupo focal. Geriatr Gerontol Aging [Internet]. 2018 [cited 2018 Sep 13];(1):31-7. Available from: http://docs.bvsalud.org/biblioref/2018/06/904987/ gga-v12n1_pt_31-37.pdf

13. Nance DC, Rivero May MI, Flores Padilla L, Moreno Nava M, Deyta Pantoja AL. Faith, Work, and reciprocity: listening to Mexican men caregivers of elderly family members. Am J Mens Health [Internet]. 2018 Nov [cited 2018 Oct 25]:12(6):1585993. Available from: https://www.ncbi.nlm.nih. gov/pubmed/27352926

14. Velasco HJ, Sanches RD, Radovanovic CA, Carreira L, Salci MA. Influences of overload in the spouse of the caregiver of the frail elderly. J Nurs UFPE On Line. 2018 [cited 2018 Sep 13];12(3):658-64. Available from: https://periodicos.ufpe.br/revistas/ revistaenfermagem/article/view/25349

15. Silva BT, Silva MRS. Necessidades e preocupações dos pais em diferentes etapas do ciclo vital. Rev bras Enferm [Internet]. 2014 [cited 2018 Oct 24];67(6):957-64. Available from: http:// www.scielo.br/pdf/reben/v67n6/0034-7167reben-67-06-0957.pdf

16. Ataka FY, Okoshi RL, Abreu YLB. Perfil epidemiológico e psicossocial dos cuidadores informais de pacientes portadores de dor crônica. Rev dor [Internet]. 2017 July/Sep [cited 2018 Oct 24];18(3):238-44. Available from: http://www.scielo.br/scielo.php?pid=S180600132017000300238\&script=sci_arttext\&tlng=pt

17. Maronesi LC, Silva NR, Cantu SD, Santos AR. Indicadores de estresse e sobrecarga em cuidadores formais e informais de pacientes 
oncológicos. Estud pesqui psicol [Internet]. 2014 [cited 2018 Oct 28];14(3):877-92. Available from: https://www.e-publicacoes.uerj.br/index.php/ revispsi/article/view/13889

18. Lampert CD, Scortegagna SA. Subjetividade e empatia no trabalho do cuidado. Farol - Rev Estud Organiz Soc [Internet]. 2015 dez [cited 2018 Oct 14];2(5):729-58. Available from: https://revistas. face.ufmg.br/index.php/farol/article/view/3133

19. Brites J. Afeto e desigualdade: gênero, geração e classe entre empregadas domésticas e seus empregadores. Cad pagu [Internet]. 2007 [cited 2018 Oct 14];(29):91-109. Available from: http://www.scielo.br/scielo.php?pid=S0104$83332007000200005 \&$ script=sci_abstract $\&$ tlng=pt

20. Andrade AM, Silva KL, Seixas CT, Braga PP. Atuação do enfermeiro na atenção domiciliar: uma revisão integrativa da literatura. Rev Bras Enferm [Internet]. 2017 [cited 2018 Oct 20];70(1):210-9. Available from: http://www.scielo.br/pdf/reben/ v70n1/0034-7167-reben-70-01-0210.pdf

21. Alencar MCB, Henemann L, Rothenbuhler R. A capacidade funcional de pacientes, e a fisioterapia em um programa de assistência domiciliar. Fisioter mov [Internet]. 2017 [cited 2018 nov. 2];21(1):11-20. Available from: https://periodicos.pucpr.br/index. $\mathrm{php/fisio/article/view/18985}$

22. Oliveira SG, Kruse MH, Sartor SF, EchevarríaGuanilo ME. Enunciados sobre la atención domiciliaria en el panorama mundial: revisión narrativa. Enferm Glob [Internet]. 2015 jul [cited 2018 Nov 2);14(39):360-74. Available from: http://scielo.isciii.es/scielo.php?script $=$ sci_ arttext\&pid=S1695-61412015000300017

23. Santana CJ, Silva M, Oliveira F, Coimbra JA, Oliveira ML, Marcon SS. Interação de um Serviço de Atendimento Móvel de Urgência com as Familias. J health sci [Internet]. 2016 [cited 2018 Nov 6];18(4):235-9. Available from: http://www. pgsskroton.com.br/seer/index.php/JHealthSci/ article/view/3497

24. Pedreira LC, Ferreira AMC, Silva GTR, Silva $\mathrm{R}$ MO, Freitas CM. Older Brazilian caregivers and their lived experiences of caring-A hermeneutic phenomenological study. J Clin Nurs [Internet]. 2018 Sep [cited 2018 Oct 25];27(17-18):3314-23. Available from: https://www.ncbi.nlm.nih.gov/ pubmed/29194844

25. Hu SX, Lei WI, Chao KK, Hall BJ, Chung SF. Common chronic health problems and life satisfaction among Macau elderly people. Int J Nurs Sci [Internet]. 2016 Dec [cited 2018 Nov 5];3(4):36770. Available from: https://www.sciencedirect. com/science/article/pii/S2352013216300229

Recebido: 12 de março de 2019

Aprovado: 17 de outubro de 2019

Publicado: 19 de dezembro de 2019

A Revista Baiana de Enfermagem utiliza a Licença Creative Commons - Atribuição-NãoComercial 4.0 Internacional.

https://creativecommons.org/licenses/by-nc/4.0/

Este artigo é de acesso aberto distribuído sob os termos da Licença Creative Commons (CC BY-NC).

Esta licença permite que outros remixem, adaptem e criem a partir do seu trabalho para fins não comerciais. Embora os novos trabalhos tenham de lhe atribuir o devido crédito e não possam ser usados para fins comerciais, os usuários não têm de licenciar esses trabalhos derivados sob os mesmos termos. 